\title{
PENGELOMPOKAN JENIS USAHA UMKM KOTA SEMARANG DALAM RANGKA PROSES PEMBINAAN DAN PENDAMPINGAN UNTUK PENGEMBANGAN USAHA DENGAN TEKNIK DATA MINING
}

\author{
Eko Nur Wahyudi ${ }^{1}$, Agus Prasetyo Utomo ${ }^{2}$, Novita Mariana ${ }^{3}$ \\ ${ }^{1,2,3}$ Fakultas Teknologi Informasi, Universitas Stikubank Semarang \\ Email : ${ }^{1}$ eko@edu.unisbank.ac.id, ${ }^{2}$ mustagus@edu.unisbank.ac.id, \\ ${ }^{3}$ novita_mariana@edu.unisbank.ac.id
}

\begin{abstract}
Abstrak
Semarang sebagai ibu kota Jawa Tengah merupakan kota pusat perdagangan dan industri dengan sektor unggulan di bidang manufaktur, agrikultur dan pariwisata. Dari sisi laju pertumbuhan ekonomi (LPE), kota Semarang mengalami peningkatan cukup signifikan yaitu 5,7 di tahun 2015 menjadi 5,8 di tahun 2016. Artinya laju pertumbuhan ekonomi masyarakatnya sangat tinggi, khususnya di sektor pariwisata. Banyak industri kecil tumbuh yang menopang laju pertumbuhan ekonomi menjadi meningkat, seperti di bidang makanan dan minuman olahan dan kerajinan. Beberapa wilayah dikhususkan dalam pengembangan industri tersebut, namun demikian tidak semua dapat menjadi sentra dari setiap bidang industri tetapi bisa disesuaikan dengan kondisi masing-masing wilayah, seperti contoh dalam usaha kerajinan batik ada di beberapa lokasi demikian juga dengan industri olahan pangan.

Pola pertumbuhan industri mikro, kecil dan menengah tersebut agar dapat dimonitor dan dikembangkan sesuai dengan potensi masing-masing wilayah industri dengan metode $\mathrm{K}$ Means untuk bisa memetakan pembinaan dan pendampingan pengembangan yang tepat sesuai dengan bidang usaha para pelaku industri mikro, kecil menengah dan potensi wilayah kecamatan.
\end{abstract}

Kata Kunci: metode K-Means, UKM Kota Semarang, Jenis Usaha UKM, Potensi Wilayah.

\section{PENDAHULUAN}

Septo Indarto Team Double S menyatakan bahwa dalam persaingan global dimana perdagangan bebas merupakan sebuah indikator dari kemajuan ekonomi sebuah Negara yang akan menciptakan sebuah kemakmuran dan kemajuan ekonomi, maka wirausaha adalah jalan terbaik untuk mewujudkan hal itu semua. Masyarakat yang tadinya pasif (mencari kerja) diubah menjadi masyarakat yang proaktif (menciptakan lapangan kerja) intinya adalah sebuah perubahan mindset (cara berpikir). Karena maju mundurnya sebuah bangsa ditentukan oleh daya saing disemua bidang, antara lain daya saing ekonominya.

Dalam rangka menumbuhkan perekonomian masyarakat tersebut maka pemerintah membuat kebijakan untuk mengembangkan kewirausahaan diseluruh wilayah Indonesia. Melalui kementerian terkait pemerintah menekankan pentingnya mengembangkan kewirausahaan pada masyarakat luas, tujuannya agar pertumbuhan perekonomian di tingkat masyarakat bawah juga berkembang dan pada akhirnya akan mendukung perekonomian nasional.

Perlu dipahami bersama bahwa perekonomian industri kecil dan menengah akan menopang secara kuat perekonomian negara apabila program kewirausahaan ini berhasil. Agar program kewirausahaan dapat tumbuh dengan cepat maka tidak hanya pemerintah yang membuat kebijakan dengan kementerian terkait sebagai pelaksananya, namun juga perlu dukungan instansi swasta dan peran masyarakat itu sendiri menuju keberhasilan. 
Untuk saat ini jumlah wirausaha di Indonesia baru mencapai 3\% dari populasi penduduk Indonesia yang berjumlah 265 juta orang pada 2018. Hal tersebut menunjukkan perlunya pertumbuhan yang pesat guna memiliki daya saing di tingkat regional dan internasional. Perekonomian negara akan stabil dengan memiliki jumlah wirausaha sebesar 5\% dari jumlah penduduknya. Sebagai pembanding 7 negara dengan jumlah wirausaha terbanyak yaitu, Vietnam (3,3\%), Thailand (4,5\%), Malaysia (5\%), Singapura (7\%), Tiongkok (10\%), Jepang (11\%), Amerika (12\%). Hal itu menyimpulkan bahwa negara-negara maju pun ditopang oleh jumlah wirausaha yang tinggi. Untuk mengejar ketertinggalan tersebut maka Indonesia harus dengan kerja keras dan segala usaha mengupayakan capaian 5\%.

Semarang sebagai ibu kota Jawa Tengah merupakan kota pusat perdagangan dan industri dengan sektor unggulan di bidang manufaktur, agrikultur dan pariwisata. Dari sisi laju pertumbuhan ekonomi (LPE), kota Semarang mengalami peningkatan cukup signifikan yaitu 5,7 di tahun 2015 menjadi 5,8 di tahun 2016. Artinya laju pertumbuhan ekonomi masyarakatnya sangat tinggi, khususnya di sektor pariwisata. Banyak industri kecil tumbuh yang menopang laju pertumbuhan ekonomi menjadi meningkat, seperti di bidang makanan dan minuman olahan dan kerajinan, Beberapa wilayah dikhususkan dalam pengembangan industri tersebut, namun demikian tidak semua dapat menjadi sentral dari setiap bidang industri tetapi bisa disesuaikan dengan kondisi masing-masing wilayah, seperti contoh dalam usaha kerajinan batik ada di beberapa lokasi demikian juga dengan industri kulinernya.

\section{METODOLOGI PENELITIAN}

Langkah pertama yang dilakukan adalah mengambil data UMKM di semua kecamatan yang tersedia di pemerintah kota Semarang. Terdapat sekitar sepuluh ribu lebih data yang ada, namun tidak semuanya lengkap sesuai dengan isian yang seharusnya. Data tersebut kemudian diperbaiki melalui proses cleaning data, yaitu data yang kosong atau kurang dilengkapi, data yang salah tulis diperbaiki, sedangkan data yang sangat kurang lengkap dihapus dengan jumlah yang relatif sangat sedikit, seperti pada gambar 1 .

\begin{tabular}{|l|l|l|l|l|l|}
\hline SMA/SMK/MA & 2015 & Chifon cake & Olahan Pangan & Milik Sendiri & \\
\hline SMA/SMK/MA & 2012 & Mie ayam & Olahan Pangan & Sewa & Lain-lain \\
\hline Akademi & 2013 & Jasa & Lainnya & Milik Sendiri & \\
\hline SMA/SMK/MA & 2014 & Soto \& elektronik & Lainnya, Olahan Pangan & Milik Sendiri & \\
\hline SMA/SMK/MA & 2015 & - & Lainnya & Milik Sendiri & \\
\hline SMA/SMK/MA & 2006 & Sembako & Lainnya & Milik Sendiri & \\
\hline SMA/SMK/MA & 2003 & Makanan & Olahan Pangan & Milik Sendiri & \\
\hline SMA/SMK/MA & 1993 & Sembako & Lainnya & Milik Sendiri & Lain-lain \\
\hline Akademi & 2016 & Sambal kemasan & Olahan Pangan & Sewa & \\
\hline SMA/SMK/MA & 2001 & Kue kering & Olahan Pangan & Milik Sendiri & Lain-lain \\
\hline SD/MI & 2013 & Sembako & Lainnya & Milik Sendiri & Pinjaman Bank \\
\hline SMA/SMK/MA & 2014 & Jasa & Lainnya & Sewa & Lain-lain \\
\hline SMP/MTs & 2008 & Rosok & Lainnya & Milik Sendiri & Pinjaman Bank \\
\hline SMA/SMK/MA & 2015 & Air dalam kemasan & Lainnya & Milik Sendiri & \\
\hline SMA/SMK/MA & 2002 & Roti dan souvenir & Olahan Pangan & Milik Sendiri & Lain-lain \\
\hline SMP/MTs & 1999 & Kecantikan & Lainnya & Milik Sendiri & Lain-lain \\
\hline
\end{tabular}

Gambar 1. Data awal yang mengalami proses Cleaning Data

Proses selanjutnya adalah memilih judul kolom yang sesuai untuk diolah. Kolom yang dipilih harus sesuai dengan proses yang akan dilakukan dan hasil tujuan akhir yang diharapkan. Adapun atribut/kolom yang dipilih yaitu : id, namausaha, pemilik, wilayah kecamatan, wilayah kelurahan, jenis usaha, sarana usaha dan omset. 


\section{Pengolahan Data dengan Rumus Matematika/Statistik}

Berdasarkan judul kolom tersebut kemudian dilakukan proses pengolahan data dengan rumus matematika dan statistik antara lain menghitung jumlah, nilai minimum, nilai maksimum dan nilai rata-rata, seperti terlihat pada gambar berikut :

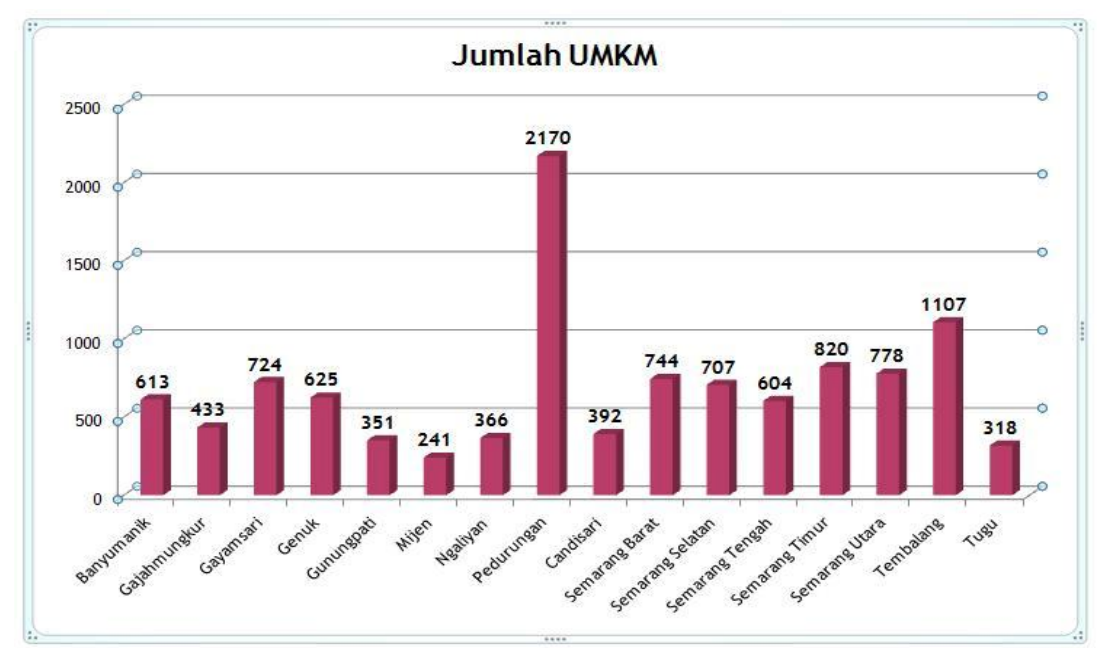

Gambar 2. Jumlah UMKM per wilayah kecamatan

Terdapat 23 jenis usaha yang tersebar di semua wilayah kecamatan, yaitu :
a. olahan pangan, 4.282
m. pakaian, 338
b. air mineral, 98
n. kos-kosan, 171
c. bandeng, 124
o. lunpia, 60
d. handycraft, 409
p. logam, 136
e. batik, 131
q. perikanan, 28
f. jamu, 83
r. peternakan, 59
g. pariwisata, 30
s. angkot, 11
h. kelontong, 291
t. meubel, 95
i. bengkel, 187
u. pertanian, 73
j. warung makan, 104
v. farmasi, 2
k. bahan pangan, 181
w. lainnya, 3.222

1. sembako, 878

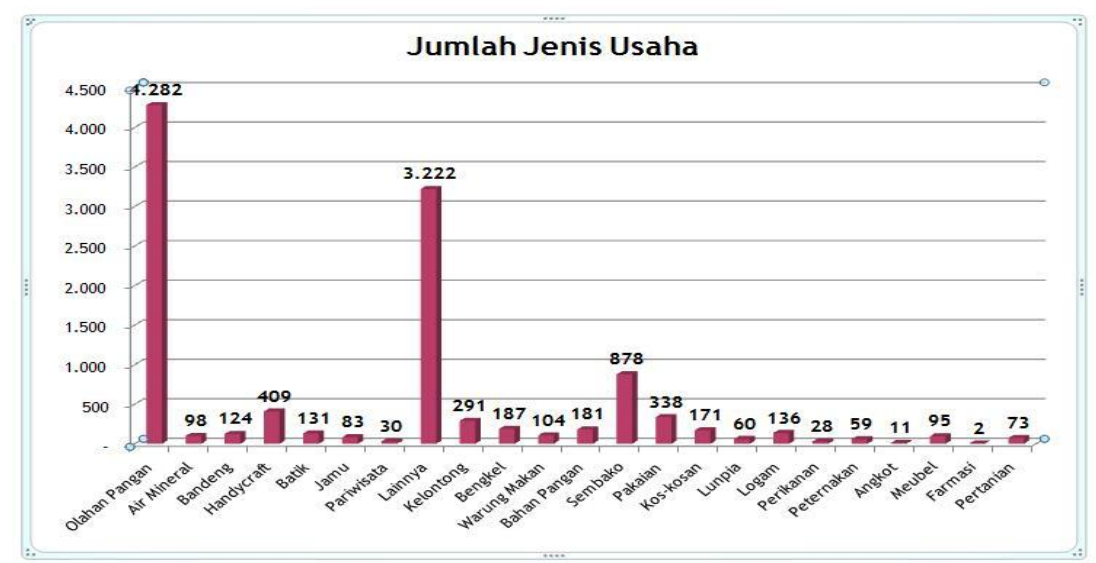

Gambar 3. Jumlah Jenis Usaha 


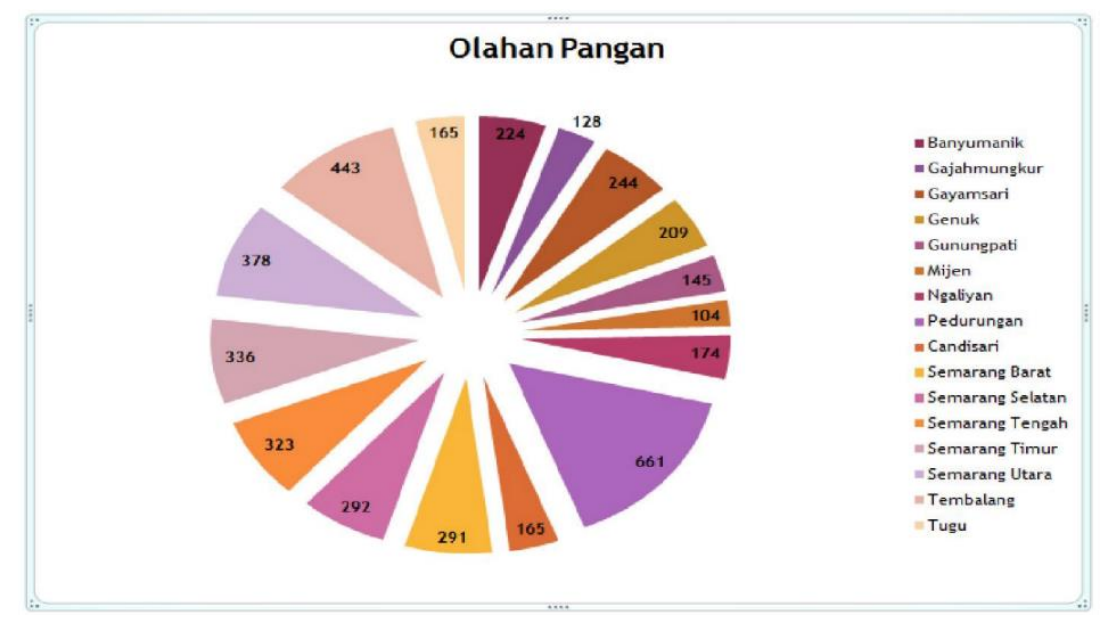

Gambar 4. Jenis Usaha Olahan Pangan per Kecamatan

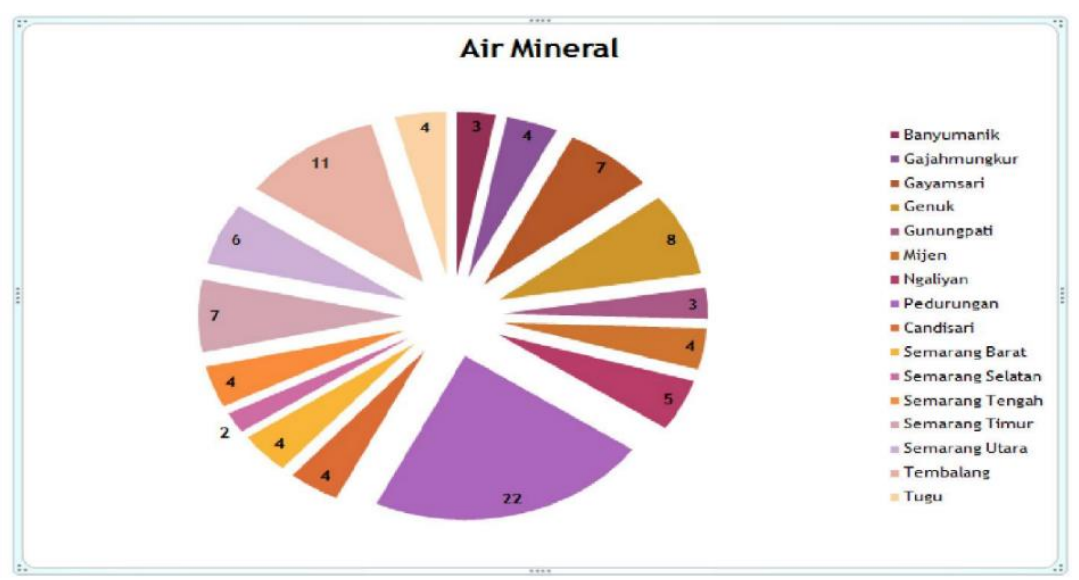

Gambar 5. Jenis Usaha Air Mineral per Kecamatan

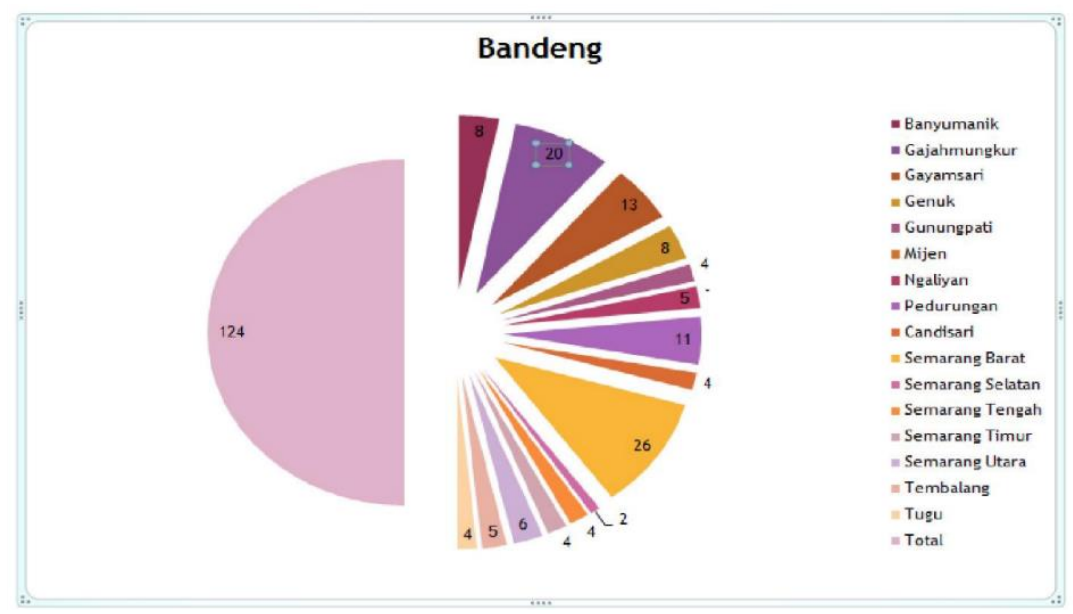

Gambar 6. Jenis Usaha Bandeng per Kecamatan 


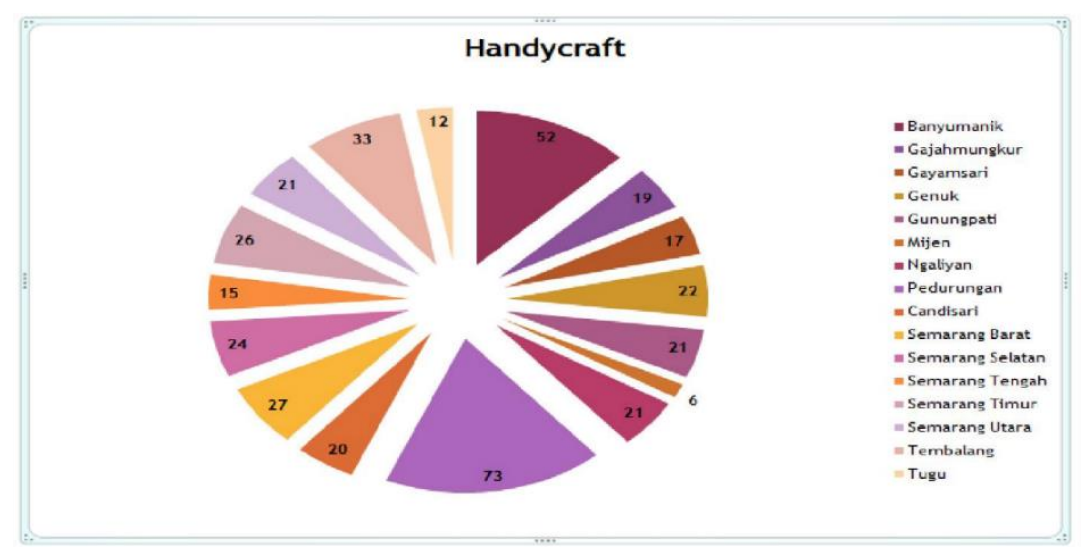

Gambar 7. Jenis Usaha Handycraft per Kecamatan

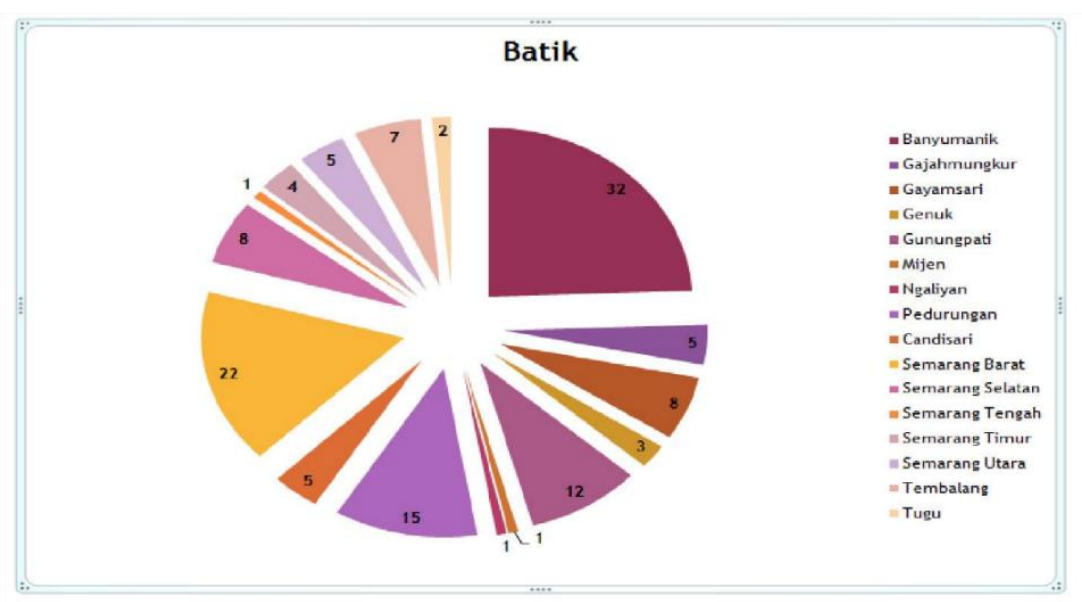

Gambar 8. Jenis Usaha Batik per Kecamatan

Berdasarkan proses pengolahan data dengan rumus matematika/statistik maka diperoleh hasil sebagai berikut:

a. Jumlah UMKM berdasarkan wilayah kecamatan cukup bervariasi antara yang terendah di kecamatan Mijen sebanyak 241 hingga yang terbanyak di kecamatan Pedurungan sebanyak 2.170.

b. Jenis usaha olahan pangan merupakan jenis usaha terbanyak dengan jumlah 4.282, didominasi oleh kecamatan Pedurungan dengan jumlah sebanyak 661, diikuti berikutnya oleh kecamatan Tembalang dengan jumlah sebanyak 443 dan kecamatan Semarang Utara dengan jumlah sebanyak 378 .

c. Peringkat jenis usaha terbanyak berikutnya adalah lainnya, yaitu sebanyak 3.222, yang terdiri atas jenis usaha antara lain buruh cuci, pertukangan, usaha sablon, pelukis, reparasi jam, dll. Untuk jenis usaha ini didominasi oleh kecamatan Pedurungan sebanyak 808, kemudian kecamatan Tembalang sebanyak 312, dan berikutnya adalah kecamatan Semarang Timur sebanyak 243.

d. Jenis usaha ketiga terbanyak adalah sembako dengan jumlah 878. Kecamatan Pedurungan dengan 285 menduduki jumlah paling banyak, berikutnya adalah kecamatan Tembalang dengan jumlah 83, dan selanjutnya kecamatan Genuk dengan jumlah 61.

e. Jenis usaha lain jumlahnya sangat bervariasi tergantung dari wilayah kecamatan masingmasing, misalnya seperti kecamatan Tembalang dengan jumlah jenis usaha kos-kosan terbanyak yaitu 38 karena lokasinya terdapat beberapa kampus besar. Selanjutnya kecamatan Pedurungan dengan jumlah 31 mengingat banyak tempat industri di wilayah tersebut. Jumlah jenis usaha kos-kosan sendiri mencapai 171. 
f. Jenis usaha pakaian dan handycraft termasuk banyak, yaitu 409 dan 338, tersebar di berbagai wilayah kecamatan, mengingat kedua jenis usaha ini merupakan kebutuhan akan sandang dan peminatan terhadap barang kerajinan tangan.

\section{PEMBAHASAN}

Tidak semua data ditampilkan dalam grafik. Selanjutnya dengan menggunakan rumus Kmeans data jumlah jenis usaha diproses untuk mendapatkan beberapa kluster menurut jenis usaha yang mereka miliki. Data jenis usaha akan diklaster menjadi 3 (tiga) kelompok dengan penilaian dari yang terendah hingga tertinggi sebagai berikut :

K-means :

a. Tentukan jumlah klaster

b. Alokasikan data ke dalam klaster secara random

c. Hitung centroid/rata-rata dari data yang ada di masing-masing cluster

d. Alokasikan masing-masing data ke centroid/rata-rata terdekat

e. Kembali ke Step 3, apabila masih ada data yang berpindah klaster atau apabila perubahan nilai centroid, ada yang di atas nilai threshold yang ditentukan atau apabila perubahan nilai pada objective function yang digunakan di atas nilai threshold yang ditentukan

Hasil dari proses tersebut seperti tampak pada gambar 9 di bawah ini :

\begin{tabular}{|c|c|c|c|c|}
\hline Klasten1 & Klaster2 & Klaster3 & Jenis Usaha & Jumlan \\
\hline \multirow[t]{7}{*}{4.282} & & & Olahan Pangan & 4.282 \\
\hline & & 98 & Air Mineral & 98 \\
\hline & & 124 & Bandeng & 124 \\
\hline & 409 & & Handycraft & 409 \\
\hline & & 131 & Batik & 131 \\
\hline & & 83 & Jamu & 83 \\
\hline & & 30 & \begin{tabular}{|l|} 
Pariwisata \\
\end{tabular} & 30 \\
\hline \multirow[t]{16}{*}{3.222} & & & Lainnys & 3.222 \\
\hline & 291 & & Kelontong & 291 \\
\hline & & 187 & Bengkel & 187 \\
\hline & & 104 & Warung Makan & 104 \\
\hline & & 181 & Bahan Pangan & 181 \\
\hline & 878 & & Sembako & 878 \\
\hline & 338 & & Pakaian & 338 \\
\hline & & 171 & Kos-kosan & 171 \\
\hline & & 60 & Lunpia & 60 \\
\hline & & 136 & Logam & 136 \\
\hline & & 28 & Perikanan & 28 \\
\hline & & 59 & Peternakan & 59 \\
\hline & & 11 & Angkot & 11 \\
\hline & & 95 & Meubel & 95 \\
\hline & & 2 & Farmasi & 2 \\
\hline & & 73 & Pertanian & 73 \\
\hline
\end{tabular}

9. Klaster UMKM berdasarkan Jenis Usaha

Kemudian jika disusun dalam bentuk tabel sesuai dengan hasil klaster yang dihasilkan akan tampak seperti pada gambar 10 .

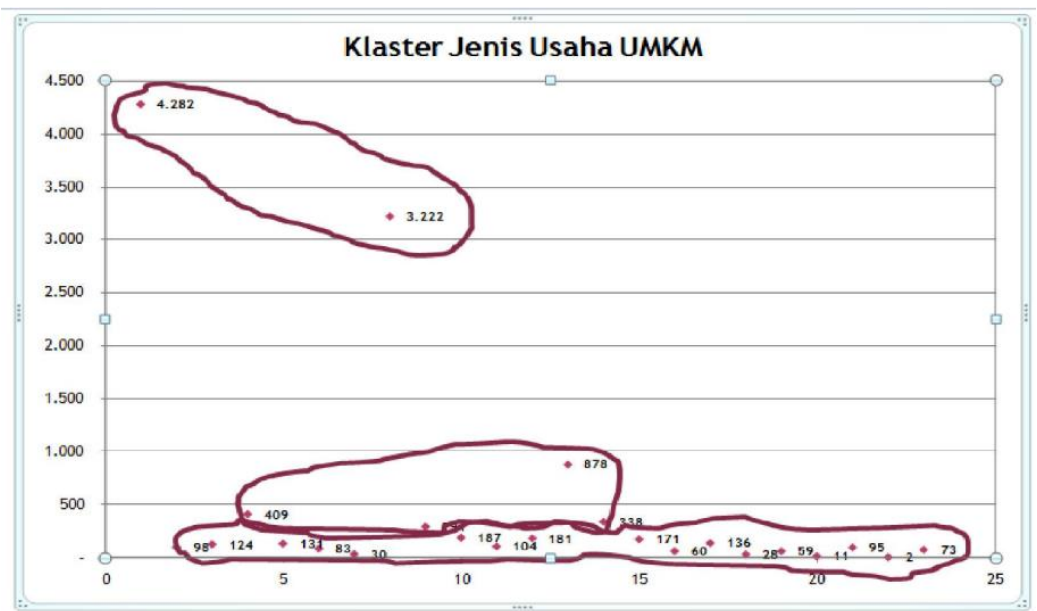

Gambar 10. Visualisasi Klaster UMKM berdasarkan Jenis Usaha 


\subsection{Hasil Pengolahan Data Dengan Rumus K-Means}

Data yang diolah dengan rumus K-means adalah jenis usaha. Hal tersebut bertujuan untuk mengetahui sejauh mana jenis usaha terkelompok menurut jumlah dan sebaran di masing-masing wilayah kecamatan. Berdasarkan hasil klaster terbentuk 3 kelompok jumlah, yaitu Klaster 1 (3.222-4282), Klaster 2 (291-878), dan Klaster 3 (2-187) :

a. Klaster 1
1) Olahan Pangan (4.282)
2) Lainnya (3.222)

b. Klaster 2
1) Handycraft (409)
2) Kelontong (291)
3) Sembako (878)
4) Pakaian (338)

c. Klaster 3
1) Air Mineral 98
2) Bandeng (124)
3) Batik (131)
4) Jamu (83)
5) Pariwisata (30)
6) Bengkel (187)
7) Warung Makan (104)
8) Bahan Pangan (181)
9) Kos-kosan (171)
10) Lunpia (60)
11) Logam (136)
12) Perikanan (28)
13) Peternakan (59)
14) Angkot (11)
15) Meubel (95)
16) Farmasi (2)
17) Pertanian (73)

\section{SIMPULAN}

a. Data UMKM kota Semarang yang diolah dengan rumus matematika dan statistik sederhana dapat menghasilkan informasi yang sangat bermanfaat sebagai bahan dasar pengambilan keputusan manajemen dalam penyusunan rencana strategis dalam upaya pengembangan kewirausahaan di wilayah kota Semarang pada khususnya.

b. Hasil pengolahan data dengan rumus matematika dan statistik menunjukkan informasi pola pertumbuhan jenis usaha yang dipilih oleh pelaku usaha lebih banyak ke jenis usaha olahan makanan, produk sembako dan kebutuhan pokok masyarakat lainnya daripada memilih produk dengan karakteristik khusus, bahkan yang bertema kearifan lokal.

c. Jenis usaha UMKM masih sangat didominasi oleh jenis olahan pangan dan lainnya (diantaranya meliputi usaha bidang khusus seperti jual beli pulsa, keahlian memijat, melukis, dll)

d. Jenis usaha yang kedua meliputi handycraft, kelontong, sembako dan pakaian

e. Jenis usaha terakhir meliputi banyak jenis usaha yang menyebar tidak merata di semua kecamatan, bahkan ada yang hanya ada di beberapa kecamatan tertentu, seperti logam, pertanian, perikanan dan peternakan 


\section{SARAN}

a. Data yang ada sebaiknya disimpan dengan format database standar agar dapat diolah dengan lebih mudah untuk menghasilkan informasi yang lebih lengkap sesuai kebutuhan manajemen pemangku pengambil kebijakan dan masyarakat.

b. Update atau pembaharuan data perlu dilakukan dengan jangkauan waktu antara 3 hingga 6 bulan sekali mengingat usaha kecil dan menengah cenderung cepat berubah seiring perjalanan waktu.

c. Data yang diolah bisa dikembangkan dengan jangkauan lebih luas yaitu pada seluruh kecamatan di wilayah kota Semarang, dan data terbaru yang digunakan hingga satu tahun terakhir.

d. Perlunya program pemerataan jenis usaha di semua kecamatan

e. Perlunya pembinaan khusus bagi jenis usaha yang mencirikan kota semarang

f. Perlunya fokus pengembangan jenis usaha tertentu sesuai dengan kondisi masing-masing wilayah kecamatan

g. Perlunya pengolahan data yang lebih lengkap, lebih baik dan terintegrasi guna monitoring dan evaluasi setiap UMKM

\section{DAFTAR PUSTAKA}

[1] Berry, M., J., A., \& Linoff, G., S., (2000). Mastering Data Mining. New York: Wiley.

[2] Chong Ho Yu, Samuel Digangi, Angel Kay Jannasch-Pennell \& Charles Kaprolet (2008). Profiling Students Who Take Online Courses Using Data Mining Methods, Arizona State University

[3] Han, J., Kamber, M. (2000). Data mining: Concepts and Techniques. New York: Morgan-Kaufman

[4] Intan Andriani, Nina Widowati (2017). Pengembangan Industri Kecil Dan Menengah Di Kota Semarang (Studi Kasus Pada Dinas Perindustrian Dan Perdagangan Kota Semarang Di Bidang Perindustrian), Journal of Public Policy and Management Review, Universitas Diponegoro

[5] James Otto, Douglas Sanford \& William Wagner (2005). Analisys Of Online Student Ratings Of University Faculty, Towson University \& Villanova University

[6] Lynda Rahmawati, Sari Widya Sihwi, Esti Suryani (2014), Analisa Clustering Menggunakan Metode K-Means Dan Hierarchical Clustering (Studi Kasus : Dokumen Skripsi Jurusan Kimia, Fmipa, Universitas Sebelas Maret), ITSMART: Jurnal Teknologi dan Informasi, Universitas Sebelas Maret

[7] Qasem A. Al-Radaideh, Emad M. Al-Shawakfa dan Mustafa I. Al-Najjar (2006). Mining Student Data Using Decision Trees, Yarmouk University

[8] Sarita Novie Damayanti, Rimadewi Suprihardjo (2016). Pembentukan Cluster Objek Daya Tarik Wisata (ODTW) di Kota Yogyakarta, Jurnal Teknik ITS, Institut Teknologi Surabaya

[9] Senol Zafer Erdogan \& Mehpare Timor (2005). A Data Mining Application In A Student Database, Maltepe University \& Istambul University.

[10] Witten, I. H., \& Frank, E. (2000). Data Mining. New York: Morgan-Kaufmann. 